\title{
Carbon transport between a euhaline vegetated marsh in South Carolina and the adjacent tidal creek: contributions via tidal inundation, runoff and seepage*
}

\author{
Thomas G. Wolaver ${ }^{1}$, John D. Spurrier ${ }^{2}$ \\ ${ }^{1}$ Belle Baruch Institute for Marine Biology and Coastal Research, University of South Carolina, Columbia, South Carolina \\ 29208 , USA \\ ${ }^{2}$ Department of Statistics, University of South Carolina, Columbia, South Carolina 29208, USA
}

\begin{abstract}
Exchange of organic carbon (DOC and POC) between a euhaline vegetated marsh and an adjacent tidal creek (North Inlet, South Carolina) was studied on 40 tidal cycles between 15 Apr 1983 and 19 Jun 1984. A flume was utilized to evaluate the role of the vegetated marsh in processing carbon during tidal inundation and a drainage weir was used to measure export from the marsh via runoff and seepage during low tide exposure (including storm events). Mean flood water DOC concentrations varied seasonally from 3.1 to $18.6 \mathrm{ppm}$. Maximum concentrations were observed in late winter and early spring, and were associated with freshwater discharge from the adjacent forest. There was a statistically insignificant $(\alpha=0.05)$ DOC import to the vegetated marsh during tidal inundation of $2.9 \mathrm{~g} \mathrm{C} \mathrm{m}^{-2} \mathrm{yr}^{-1}$. Mean flood water POC concentrations varied seasonally between 0.7 and $4.6 \mathrm{ppm}$ with the highest values observed during the summer The vegetated marsh was a sink for POC during tidal inundation except when storm events occurred on the ebb tide. There was a statistically significant $(\alpha=0.05)$ import of POC to the vegetated marsh of $83.3 \mathrm{~g} \mathrm{C} \mathrm{m}^{-2} \mathrm{yr}^{-1}$ with the largest removal rate observed when the tidal water resided on the low marsh (tall Spartina alterniflora). Exports of DOC and POC from the marsh via runoff and seepage during low tide exposure (including rain events) were $36.2 \mathrm{~g} \mathrm{C} \mathrm{m}^{-2} \mathrm{yr}^{-1}$ and $30.6 \mathrm{~g} \mathrm{C} \mathrm{m}^{-2} \mathrm{yr}^{-1}$ The annual net exchange (imports-exports) of carbon between the marsh and the adjacent tidal creek suggests this system is a sink for POC and a source for DOC, the total organic carbon exchange being negligible. This study implies the vegetated marsh may not be the source of carbon which was found to outwell from this and other marsh-estuarine systems.
\end{abstract}

\section{INTRODUCTION}

Highly productive marshlands along the eastern US shore were suggested by Odum \& de la Cruz (1967) to be sources of carbon, particularly particulate organic carbon (POC), to the adjacent water body. Their work laid the foundation for the outwelling hypothesis, which postulated that organic matter is exported from saltmarsh wetlands into the surrounding estuary or ocean, fueling the productivity of the latter. Subsequently, many studies were undertaken to evaluate the net transport of carbon through tidal creeks in an attempt to test this hypothesis (e.g. Moore 1974, Heinle \& Flemer 1976, Happ et al. 1977, Woodwell et al. 1977. Valiela et al. 1978, Chrzanowski et al. 1982, 1983). The results from these studies indicate that both dissolved

\footnotetext{
- Contribution No. 677 of the Belle W. Baruch Library in Marine Science
}

organic carbon (DOC) and POC are exported from marsh-estuarine systems. In most cases the source of the exported DOC was attributed to processes occurring on the vegetated marsh surface such as leaching from live and dead Spartina (Gallagher et al. 1976, Turner 1978, Pakulski 1986) or diffusion from marsh sediments (Pomeroy et al. 1977) whereas the source of the outwelled POC was assumed to be marsh macrophyte productivity. These interpretations imply that the vegetated marsh itself may be a major source of carbon to the surrounding water body.

To evaluate the specific role of the vegetated marsh in the processing of carbon, studies were initiated in the Bly Creek basin (North Inlet, South Carolina, USA) to estimate the carbon exchange between the marsh and the adjacent creek during tidal inundation and the export of constituents from the marsh during low tide exposure via runoff and seepage (including rain events). This study is part of a large project - 'The Bly 
Creek Ecosystems Study' - which investigated the vegetated marsh, oyster reef, and creek bottom (groundwater) subsystems in order to assess their role in nitrogen, phosphorus, carbon, chlorophyll, adenosine triphosphate (ATP), and inorganic sediment transport within and through a marsh-estuarine basin. In this paper we (1) evaluate whether a euhaline marsh is a source or sink for carbon (POC and DOC); (2) assess the role of the low (tall Spartina alterniflora) and high marsh (medium and short Spartina) in carbon transport; (3) speculate on the physical and biological factors which control the net transport of these constituents.

\section{METHODS}

To study carbon exchange during tidal inundation a flume was constructed across a $140 \mathrm{~m}$ transect of Spartina alterniflora marsh near the upper end of the Bly Creek basin of the North Inlet salt marsh (Fig. 1) in South Carolina (USA). The flume consisted of 2 parallel walls, $2 \mathrm{~m}$ apart, which channelized tidal water from the edge of a tidal creek across the tall, medium, and short $S$. alterniflora zones on the vegetated marsh. A pilot study showed that material concentration differences inside and outside the flume were minimal on mild days. Even though the flume can locally affect wind direction and intensity on stormy days, visual observation suggests this has little effect on material concentrations in the tidal water within the flume. The flume walls were removed after each sampling period to prevent long-term effects from shading, sediment scouring, and inhibition of wrack movement during storm events. Details of the flume design are outlined by Wolaver et al. (1985).

Tidal waters in the flume were sampled over 40 complete tidal cycles, every $11.8 \mathrm{~d}$ (approximately), between 15 Apr 1983 and 19 Jun 1984. This schedule was chosen in order to sample a representative range of lunar and diel periods over each season. For each of the 40 tidal cycles, water samples were taken at 2 stations, one at the mouth of the flume adjacent to the tidal creek and another within the flume between the low and high marsh zones, ca $23 \mathrm{~m}$ from the creek bank. Water samples were taken at each station at 12 equally spaced times during tidal inundation. At each sampling site and time, water samples were taken as a function of depth (bottom, middle, top of water column) and aggregated in the field. This procedure was chosen since it was shown during a calibration study (Wolaver et al. 1985) that there were few statistically significant material concentrations differences with depth over a tidal cycle.

To study carbon export from the vegetated marsh during low tide drainage, we used a V-notched weir, similar to that employed by Gardner (1975). The weir was placed in the small tidal creek adjacent to the flume where it received drainage from ca $9000 \mathrm{~m}^{2}$ of vegetated marsh. At least 6 water samples were taken at the weir from the time ebb-tide water had left the vegetated marsh surface to the time at which drainage ceased or when tidal water from the next flood tide inundated the weir. During normal sampling 4 storm

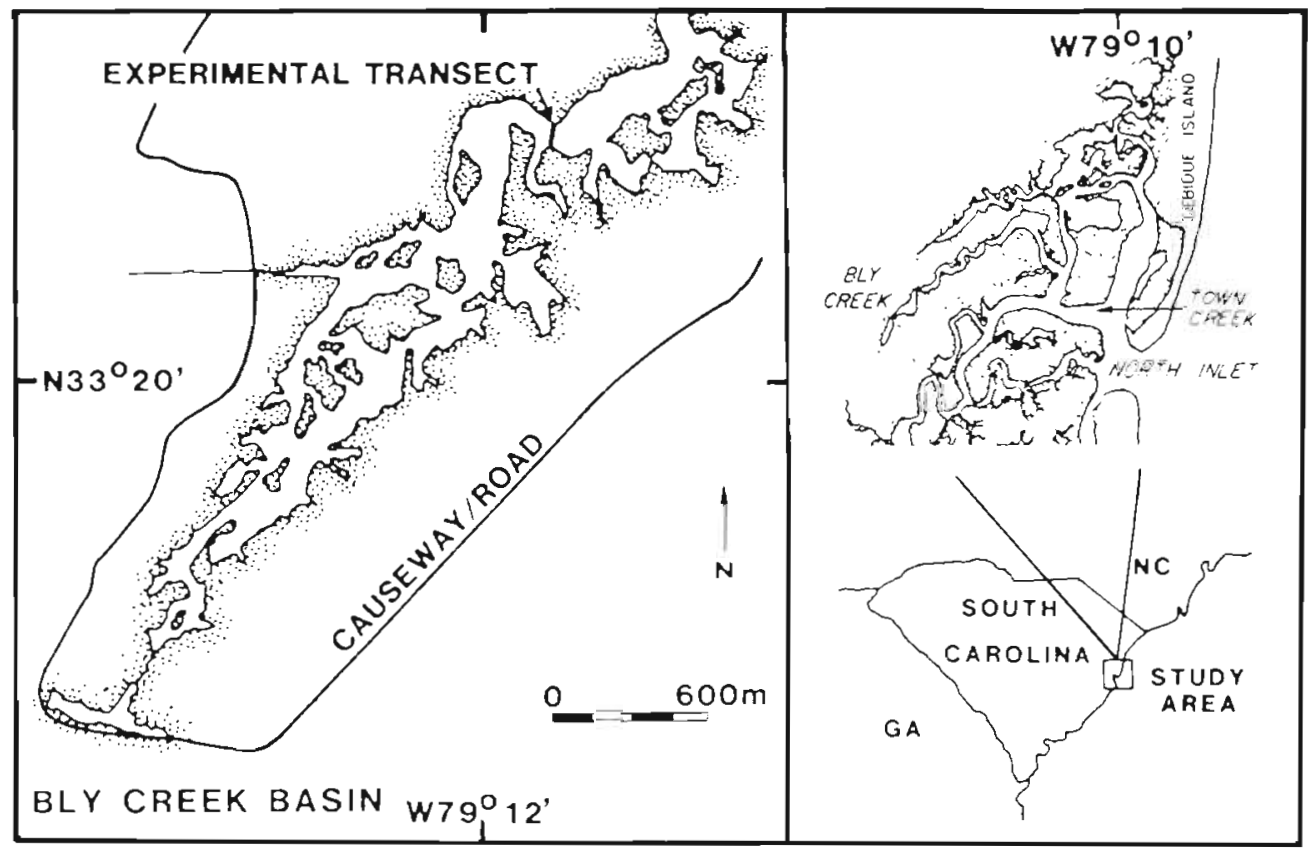

Fig. 1 Site map 
events occurred when the marsh was not inundated (16 Apr, 1 Jul, 21 Nov 1983; 13 Mar 1984).

All water samples were placed immediately on ice in the field and returned for processing to the chemistry laboratory within $2 \mathrm{~h}$ of collection. Initially, duplicate $20 \mathrm{ml}$ subsamples were filtered through $4.7 \mathrm{~cm} \mathrm{GF/C}$ filters. The latter were waved over concentrated $\mathrm{HCl}$ fumes for $20 \mathrm{~s}$ to remove the inorganic carbon fraction, inserted into ampules, and frozen for POC analysis. The filters were later dry combusted using $\mathrm{CuO}$ as an oxidant (Oceanographic International, unpubl.) with the resultant $\mathrm{CO}_{2}$ measured by infrared absorption using an Oceanographic International carbon analyzer (model $524 \mathrm{C}$ ). The remaining $200 \mathrm{ml}$ of each sample was filtered through $2.5 \mathrm{~cm} \mathrm{GF/F} \mathrm{filters,} \mathrm{and} \mathrm{the} \mathrm{fil-}$ trates refrigerated until DOC determination with a Beckman carbon analyzer (model 915A).

The instantaneous mass flux (IMF) of carbon through the flume and over the weir was calculated as a crossproduct of instantaneous discharge and nutrient concentration. IMF for each sampling was integrated over time to obtain the net flux per tidal cycle. For the flume data, this integration was accomplished by fitting a sine-cosine model to the IMF values. The latter technique provided a statistical test of significance for the net flux values. A detailed description of the modelling procedure which led to the water discharge and material flux calculations within the marsh flume is provided by Wolaver et al. (1985). Net material flux calculations were made at 2 points (Stns 1 and 2) within the flume so as to allow an assessment of how the low marsh (tall Spartina) and the high marsh (medium + short Spartina) process carbon. Since the flux of materials through Stns 1 and 2 represents how the whole marsh and high marsh are processing carbon respectively, the difference between these estimates specifies the role of the low marsh. Flux per unit area was calculated by dividing the integrated flux value by the area of marsh (low or high, etc.) inundated at high tide.

To evaluate which factors were controlling the observed carbon fluxes and to estimate the seasonal and annual exchange of material through the 2 stations within the flume, a set of 24 predictor variables (Table 1) were measured daily throughout the sampling year. We estimated our annual flux for the time period between 19 Jun 1983 and 18 Jun 1984. During this time there were 707 tidal cycles of which we sampled 34. To obtain seasonal and annual flux estimates an initial stepwise regression was performed to select a smaller set $(<24)$ of predictor variables to model the net flux per cycle for each constituent. This subset of predictor variables was further refined by

Table 1. Predictor variables used in stepwise regression analysis

\begin{tabular}{|c|c|}
\hline Variable name & Description \\
\hline TIDE & Maximum tidal height \\
\hline L1 TIDE & Maximum tidal height on previous cycle \\
\hline L2 TIDE & Maximum tidal height on second previous cycle \\
\hline RAIN & Rainfall on current cycle \\
\hline L1 RAIN & Rainfall of previous cycle \\
\hline L2 RAIN & Rainfall for second previous cycle \\
\hline R13 & Sum of rainfall $\left(>1.27 \mathrm{~cm}\right.$ event $\left.^{-1}\right)$ during tidal exposure over preceeding 8 cycles \\
\hline R14 & Sum of rainfall $\left(>25 \mathrm{~cm}\right.$ event $^{-1}$ ) over preceeding 8 cycles \\
\hline $\mathrm{BIO}$ & Biomass of live Spartina at creekside \\
\hline DERBIO & Derivative of $\mathrm{BIO}$ with respect to time \\
\hline FRESHWTR & Freshwater flow during current cycle \\
\hline L1 FRESH & Freshwater flow during previous cycle \\
\hline L2 FRESH & Freshwater flow during second previous cycle \\
\hline AWTMP & Water temperature $-18.47^{\circ}$ \\
\hline WTMP2 & Square of water temperature \\
\hline LIGHT & Proportion of tidal cycle in daylight \\
\hline L.IGHT2 & Square of LIGHT \\
\hline ALTWT & AWTMP $\times(\text { LIGHT }-0.5)^{\cdots}$ \\
\hline AWIND & Average wind speed $-8.76^{\cdots} \cdot$ \\
\hline AWNDWT & AWIND $\times$ AWTMP \\
\hline AXWIND & Maximum wind speed \\
\hline AIRTMP & Air temperature less water temperature \\
\hline L100WT & Water temperature for the $100^{\text {th }}$ previous cycle \\
\hline L100WT2 & Square of L100WT \\
\hline \multicolumn{2}{|c|}{$\begin{array}{l}\cdot 18.47=\text { average of water temperatures for sampled cycles } \\
\cdots \text { (LIGHT }-0.5)=\text { average of a variable LIGHT for sampled cycles } \\
\cdots 8.76=\text { average of average wind speeds for the sampled cycles }\end{array}$} \\
\hline
\end{tabular}


running all possible regressions and selecting the model that produced the minimum value of Mallows Cp statistic (Mallows 1973). This model was used to form the regression estimate of the net flux on an annual basis. The standard errors associated with the annual net flux estimates take into account the variability in net flux per cycle estimates as well as the error in estimating the annual net flux from the 34 sampled cycles.

\section{RESULTS AND DISCUSSION}

Mean flood DOC concentrations in the tidal water inundating the vegetated marsh varied seasonally from 3.1 to $18.6 \mathrm{ppm}$ (Fig. 2 A). The highest concentrations of DOC were observed from late winter to early spring and appear to be associated with freshwater discharge from the adjacent forest into the Bly Creek basin. This assertion is supported by a negative association between salinity and DOC in the tidal water which
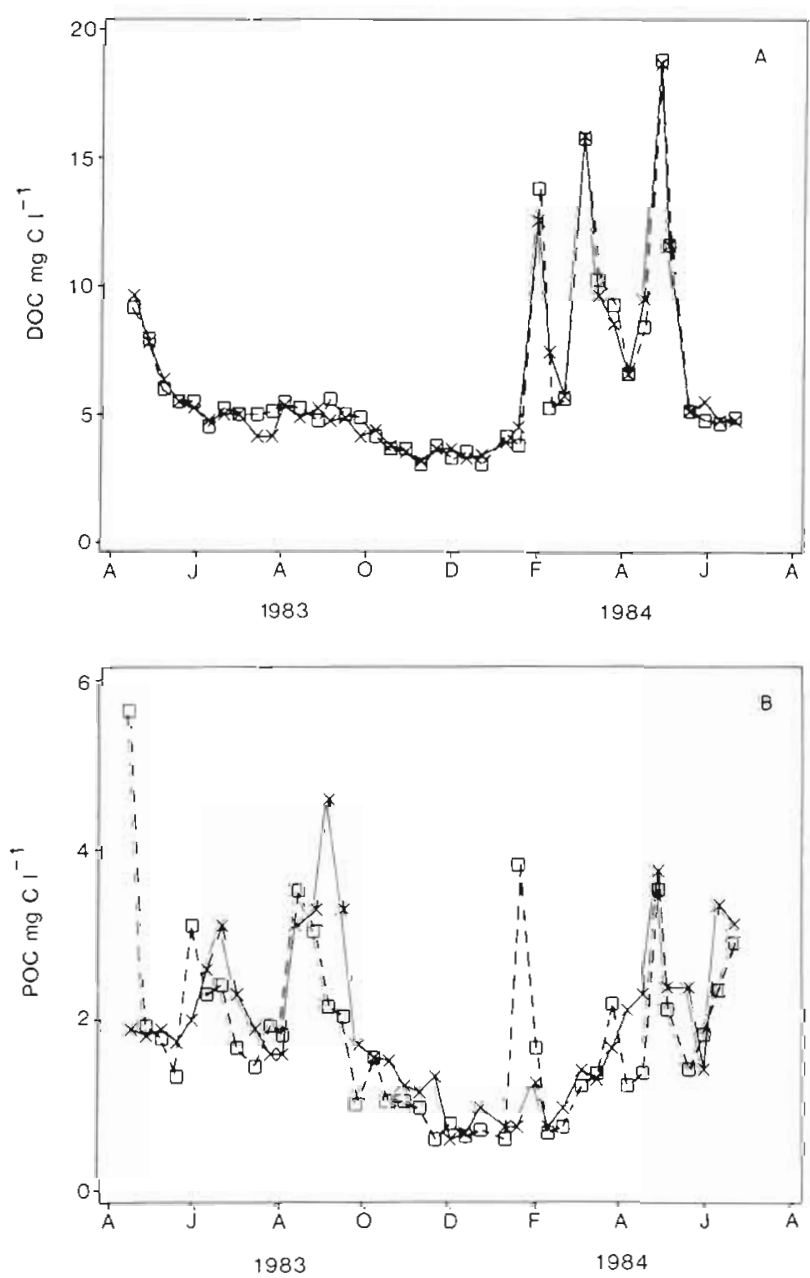

Fig. 2. Average tidal water DOC (A) and POC (B) concentrations as a function of time. $(\times)$ Flood; $(\Rightarrow)$ ebb inundated the marsh surface ( $\mathrm{r}=-0.88$ ). In addition, the seasonal rise in tidal water DOC is associated with the onset of streamflow in the late winter.

The negligible difference between flood and ebb mean DOC concentrations (Fig. 2 A) suggests that the marsh during tidal inundation is neither a source nor a sink for this constituent. This assertion is substantiated by the net fluxes of DOC which fluctuate around zero with no apparent seasonal or annual trend (Fig. 3A, Table 2). The only large DOC export from the marsh during tidal inundation was on 13 Mar 1984. This export was associated with rain which occurred when ebbing water still resided on the low marsh. It appears rain impaction and/or wave scouring caused advection of DOC from the sediments into the overlying tidal water. It should be noted that DOC fluxes are not driven by inequalities in the water budget since there were no significant differences in the amount of tidal water entering or exiting the flume on the sampied
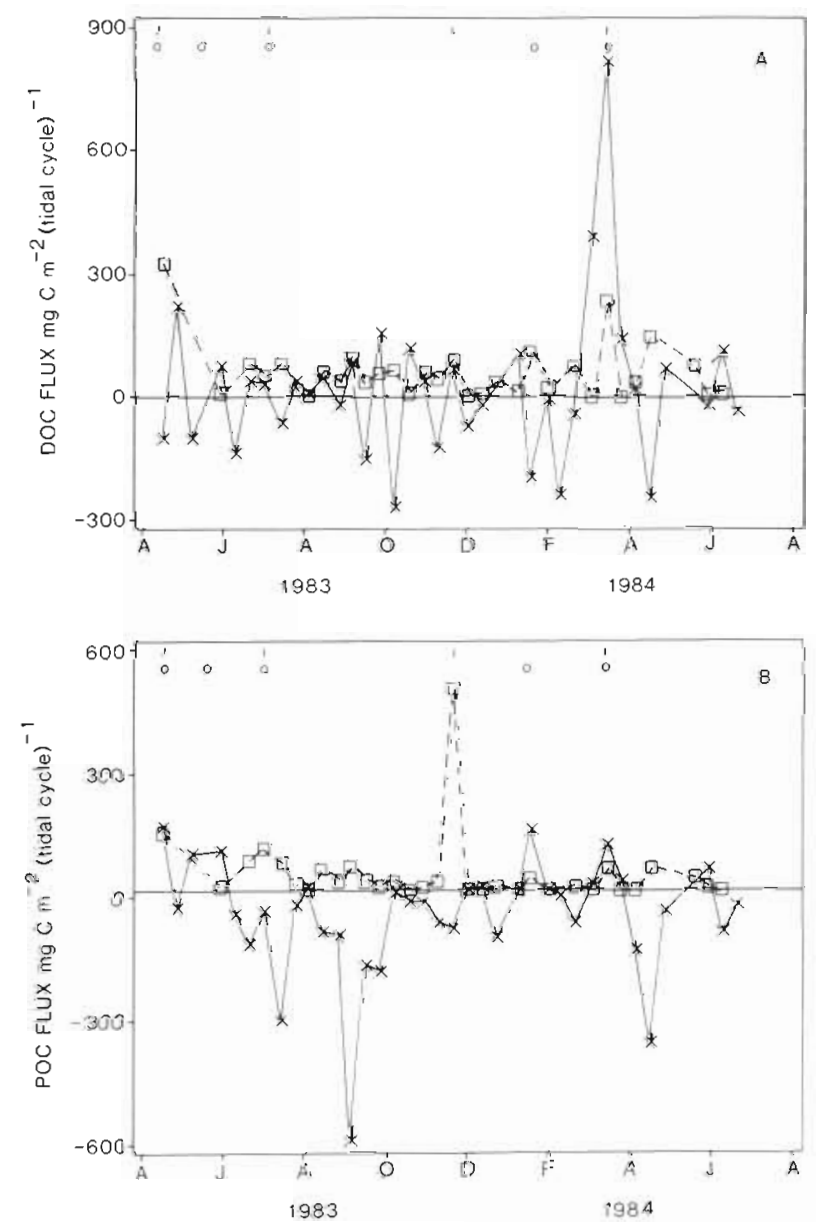

Fig. 3. Net flux of $\operatorname{DOC}(A)$ and $\operatorname{POC}(B)$ between the vegetated marsh and the adjacent tidal creek. $(\times)$ Flume study: $(\square)$ weir study. (+) Export; (-) import. Symbols at top of graph indicate rain events which occurred when tidal water was leaving the marsh surface (o) and during low-tide exposure (1) 
tides. An assessment of the role of the high and low marsh in the processing of DOC suggests that these zones are neither sources nor sinks for this constituent (Fig. $4 \mathrm{~A}$ ).

Mean POC concentrations in the tidal water inundating the marsh varied from 0.7 to $4.6 \mathrm{ppm}$ with higher values in summer (Fig. $2 \mathrm{~B}$ ). There was a bimodial peak in POC concentration during summer 1983 with the low values during late July and early August associated with a lack of rainfall during that period. In general, mean ebs POC concentrations were lower than those observed on the flood tide, suggesting the marsh was a sink for this constituent. However, there were several tidal cycles where high POC concentrations were observed on the ebb tide. The high ebb tide POC values were usually associated with wind and/or rain. The net flux data (Fig. 3 B, Table 2) suggests the marsh was normally a sink for POC during tidal inundation, especially during the summer months. POC export from the marsh was usually associated with wind or rain which occurred when ebbing water still resided on the low marsh. The partitioning of POC transport between the high and low marsh suggests both zones act as a sink for this constituent (Fig. 4 B) with the low

Table 2. Net flux of DOC and POC [gC (tidal cycle $)^{-1}$ ] through Stns 1 and $2 ;(+)$ export $(-)$ import. Net fluxes per tidal cycle $(a r e a l$ basis) were calculated from these numbers

\begin{tabular}{|c|c|c|c|c|}
\hline \multirow{4}{*}{$\begin{array}{l}\begin{array}{l}\text { Date } \\
(1983-84)\end{array} \\
\text { Apr } 15\end{array}$} & \multicolumn{4}{|c|}{ Net C flux } \\
\hline & \multicolumn{2}{|c|}{ Stn 1 (whole marsh) } & \multicolumn{2}{|c|}{ Stn 2 (high marsh) } \\
\hline & DOC & POC & DOC & $\mathrm{POC}$ \\
\hline & $-14.2 \pm 21.9$ & $20.9 \pm 4.2 \cdots$ & $-16.1 \pm 17.3$ & $6.0 \pm 4.9$ \\
\hline Apr 26 & $28.7 \pm 145.0$ & $5.3 \pm 25.7$ & $73.5 \pm 113.2$ & $15.5 \pm 25.6$ \\
\hline May 7 & $-7.3 \pm 20.2$ & $6.5 \pm 7.0$ & $-9.0 \pm 8.3$ & $-3.7 \pm 2.7$ \\
\hline May 17 & - & - & - & - \\
\hline May 28 & $9.9 \pm 18.2$ & $12.6 \pm 10.7$ & $-13.7 \pm 8.3$ & $-1.5 \pm 8.3$ \\
\hline Jun 8 & $-19.7 \pm 30.2$ & $-8.7 \pm 15.8$ & $2.1 \pm 31.3$ & $-31.0 \pm 21.4$ \\
\hline Jun 20 & $4.9 \pm 26.5$ & $-18.7 \pm 14.7$ & $-20.7 \pm 21.1$ & $3.4 \pm 6.7$ \\
\hline Jun 30 & $4.5 \pm 13.1$ & $-6.5 \pm 5.5$ & $-9.4 \pm 11.8$ & $-9.5 \pm 2.8$ \\
\hline Jul 12 & $9.3 \pm 26.5$ & $46.2 \pm 29.5$ & $16.5 \pm 22.2$ & $-18.1 \pm 14.4$ \\
\hline Jul 23 & $1.6 \pm 3.7$ & $1.6 \pm 1.7$ & $4.4 \pm 11.2 \cdots$ & $1.2 \pm 25.3$ \\
\hline Aug 3 & $0.4 \pm 1.5$ & $0.4 \pm 1.0$ & - & - \\
\hline Aug 13 & $6.6 \pm 23.2$ & $-14.2 \pm 5.0$ & $98.3 \pm 123.7$ & $13.6 \pm 17.7$ \\
\hline Aug 25 & $-3.1 \pm 9.6$ & $-14.2 \pm 12.3$ & $6.9 \pm 5.8$ & $-15.4 \pm 7.8$ \\
\hline Sep 4 & $11.7 \pm 25.6$ & $-86.6 \pm 18.6 \cdots$ & $9.3 \pm 12.8$ & $-67.2 \pm 22.1 \cdots$ \\
\hline Sep 15 & $22.2 \pm 40.6$ & $-26.6 \pm 14.7$ & $10.7 \pm 39.1$ & $-53.2 \pm 24.4$ \\
\hline Sep 25 & $21.3 \pm 20.6$ & $-26.8 \pm 14.5$ & $-0.4 \pm 21.9$ & $-17.4 \pm 3.3 \cdot$ \\
\hline Oct 10 & $39.4 \pm 24.8$ & $-1.0 \pm 63.8$ & - & - \\
\hline Oct 18 & $14.7 \pm 15.1$ & $-2.9 \pm 4.2$ & $-8.3 \pm \quad 5.1$ & $0.6 \pm 1.7$ \\
\hline Oct 29 & $1.8 \pm 2.8$ & $-1.4 \pm 1.4$ & $0.0 \pm \quad 0.4$ & $0.3 \pm 0.7$ \\
\hline Nov 9 & $17.6 \pm 22.0$ & $-11.7 \pm 8.2$ & $12.9 \pm 16.8$ & $14.9 \pm 6.5$ \\
\hline Nov 20 & $9.2 \pm 23.5$ & $-12.9 \pm 5.9$ & $7.8 \pm 30.3$ & $-4.6 \pm 2.9$ \\
\hline Nov 30 & $8.1 \pm 9.6$ & $0.5 \pm 1.9$ & $-2.7 \pm 3.8$ & $-0.7 \pm 0.7$ \\
\hline Dec 11 & $1.8 \pm$ & $0.7 \pm 1.7$ & $-0.5 \pm \quad 2.2$ & $1.2 \pm 1.1$ \\
\hline $\operatorname{Dec} 21$ & - & $-16.7 \pm 14.6$ & $-26.6 \pm 32.5$ & $0.0 \pm 12.6$ \\
\hline $\operatorname{Jan} 8$ & $13.9 \pm 8.3$ & $0.5 \pm 2.2$ & $11.2 \pm \quad 4.7$ & $0.6 \pm 5.3$ \\
\hline $\operatorname{Jan} 18$ & $-27.1 \pm 16.5$ & $20.9 \pm 26.5$ & $-27.2 \pm 13.9$ & $-4.4 \pm 1.6$ \\
\hline $\operatorname{Jan} 29$ & $-0.1 \pm 5.7$ & $0.0 \pm 0.5$ & - & - \\
\hline Feb 8 & $-9.7 \pm 5.7$ & $-0.4 \pm 0.5$ & $-0.8 \pm 2.5$ & $-1.0 \pm 0.9$ \\
\hline Feb 20 & $-5.9 \pm 14.4$ & $11.1 \pm 8.3$ & $9.2 \pm 10.8$ & $5.3 \pm 4.1$ \\
\hline $\operatorname{Mar} 2$ & $39.4 \pm 16.7$ & $1.6 \pm 3.1$ & $6.4 \pm 9.1$ & $2.2 \pm 1.4$ \\
\hline Mar 13 & $114.8 \pm 72.0$ & $15.9 \pm 10.7$ & $-19.1 \pm 46.2$ & $11.7 \pm 11.5$ \\
\hline Mar 23 & $5.3 \pm 8.5$ & $0.9 \pm 1.2$ & - & - \\
\hline Apr 4 & $3.2 \pm 38.5$ & $-19.4 \pm 6.7$ & $22.8 \pm 24.8$ & $7.9 \pm 8.1$ \\
\hline Apr 14 & $-36.4 \pm 129.0$ & $-54.9 \pm 26.8$ & $-12.9 \pm 87.5$ & $-37.5 \pm 19.4$ \\
\hline Apr 25 & $3.4 \pm 11.2$ & $-2.4 \pm 1.9$ & $4.6 \pm 8.8^{\circ}$ & $3.6 \pm 1.4^{\cdots}$ \\
\hline May 6 & - & - & - & - \\
\hline May 17 & $113.8 \pm 37.1$ & $-5.1 \pm 13.4$ & - & - \\
\hline May 28 & $1.6 \pm 10.6$ & $4.1 \pm 2.2$ & $9.0 \pm 5.4$ & $2.1 \pm 1.9$ \\
\hline Jun 8 & $14.1 \pm 13.3$ & $-13.9 \pm 10.0$ & $10.0 \pm 15.5$ & $-3.9 \pm 2.8$ \\
\hline Jun 19 & $2.0 \pm 2.2$ & $2.0 \pm 3.7$ & $0.7 \pm 1.5$ & $2.1 \pm 3.8$ \\
\hline
\end{tabular}


marsh (tall Spartina) more important on an areal basis. However, large exports from the low marsh were occasionally observed, most of these associated with rain or wind.

Export of DOC from the marsh via runoff and seepage varied from 9 to $320 \mathrm{mg} \mathrm{C} \mathrm{m}^{-2}$ (tidal cycle) ${ }^{-1}$ with little seasonal trend (Fig. $3 \mathrm{~A}$ ). POC export via this process varied from 0 to $550 \mathrm{mg} \mathrm{C} \mathrm{m}^{-2}$ (tidal cycle) $^{-1}$ with most of the flux values less than $75 \mathrm{mg} \mathrm{C} \mathrm{m}^{-2}$ (tidal cycle) $^{-1}$ (Fig. 3 B). Runoff and seepage of POC for the storms on 1 Jul and 21 Nov 1983 are estimates based on a regression between inorganic sediment and POC flux for the remaining 32 sampling periods $(\mathrm{r}=0.94)$. This was necessary due to difficulties in POC determination on samples with high particulate load. The available POC data during the above-mentioned storms suggest the calculated carbon flux may overestimate the actual values. Runoff and seepage of DOC and POC was particularly important at this site since a topographic depression was found at the rear of the
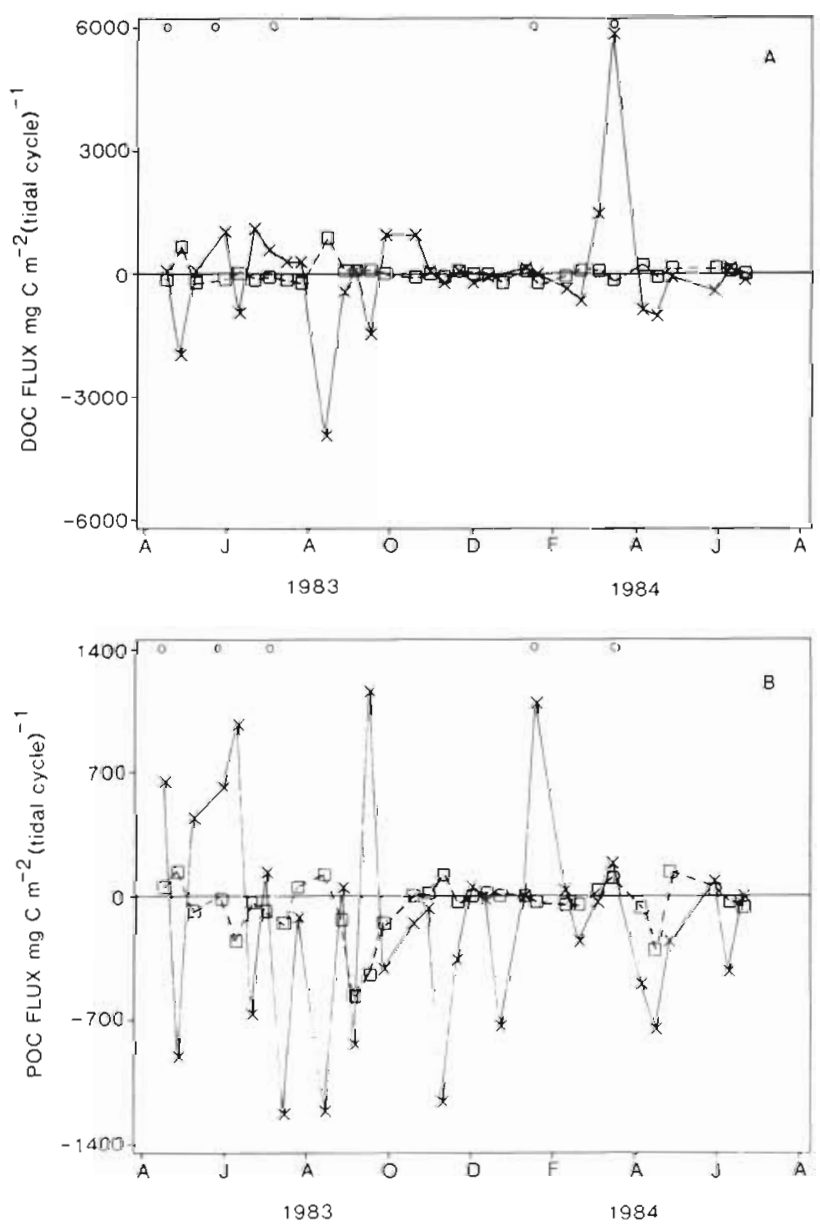

Fig. 4. Net flux of DOC (A) and POC (B) during tidal inundation as a function of vegetation zone. $(x)$ Low marsh; $\Leftrightarrow$ high marsh. (+) Export; (-) import. Symbols at top of graph indicate rain events which occurred when tidal water was leaving marsh surface (o) short Spartina zone. This marsh feature allowed for storage of tidal water (up to $4 \mathrm{~cm}$ deep) in the high marsh when the tidal water had left this zone. This water subsequently drained off the marsh surface with its associated constituents during low tide exposure. The importance of the effect of water discharge on DOC export via runoff and seepage is illustrated by the strong correlation between these 2 variables $(\mathrm{r}=0.91)$. Normally the depth of water left on a marsh surface when the tidal water has receded below bank-full is 1 to $2 \mathrm{~mm}$ (Gardner 1975). The enhanced DOC export from the marsh caused by the excess storage of tidal water when the preceeding tide inundated the high marsh (tide ht. $>60 \mathrm{~cm}$ ) is depicted in Fig. 5. The circled values in this figure show the additional effect of rain which occurred during the sampling period or the day before. It appears that rainstorms can increase the export of DOC from the marsh (runoff and seepage) by (1) disturbance to the sediment substrate with a commensurate release of interstitial DOC or (2) additional runoff from near the marsh-upland border caused by elevated groundwater levels. Diffusion and seepage of DOC from sediments into the runoff water also occurred since DOC concentrations in runoff and seepage water were higher than those found in tidal water during the summer and fall months. For POC the largest exports via runoff and seepage are associated with rain events occurring during tidal exposure. This is illustrated by the large export observed on $23 \mathrm{Nov}$

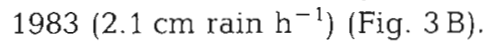

A statistical analysis was conducted to (1) evaluate the factors which may be responsible for the observed carbon fluxes during tidal inundation and (2) estimate annual budgets for material exchange between the vegetated marsh and the adjacent tidal creek. To determine which factors may be responsible for the net fluxes of DOC and POC within the flume, a correlation

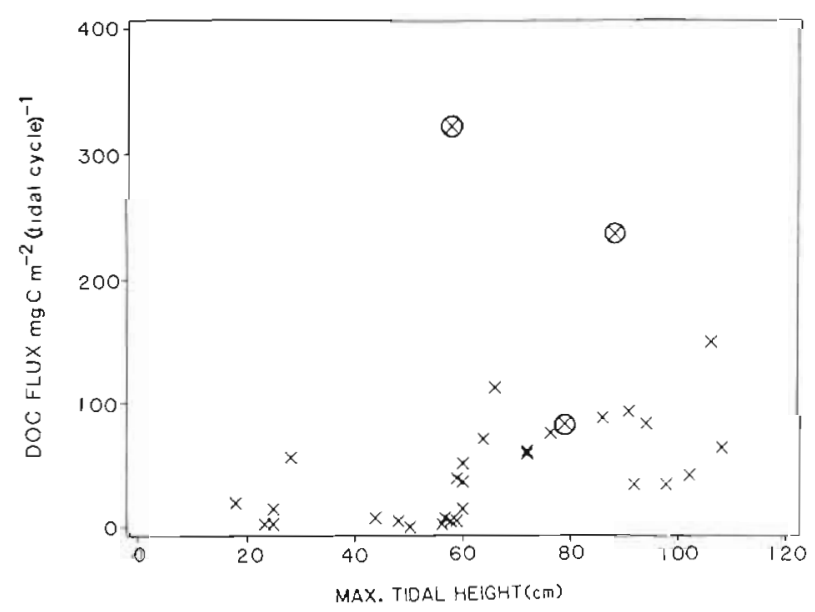

Fig. 5. DOC export via runoff and seepage versus maximum tidal height of preceeding tide. Circled values: rain during sampling period or day before 
analysis was performed using some of the pertinent data collected in the flume study, in addition to a subset of the physical predictor variables (Table 1). The correlation analysis for DOC resulted in few significant associations (Table 3). In general, these results are not surprising since the bulk of the tidal water DOC has its source in the blackwater stream entering the Bly Creek basin. This stream drains a cypress-pine forest and probably contains high concentrations of refractile humic and fulvic acids. The associations of light, ATP, and chl a with the DOC flux onto and off the high marsh (Stn 2) suggests the possible importance of microbial activity in controlling DOC transport (Table 3).

The correlation analysis for POC suggests that the net transport of this constituent is associated with POC concentrations in the flooding water, tidal height (analogous to duration of inundation), water temperature, and storms (Table 3). This implies that the largest imports of POC to the marsh occurred on high tides during the summer when high POC concentrations were observed in the tidal water, especially following storms. This scenario is depicted in Fig. 6, which shows the relation between POC transport, season, and maximum tidal height for each sampling. It is hypothesized that $\mathrm{POC}$ is removed from the flooding water by the filtering effect of grass stems, sorption on epiphytic threads associated with these plants, and/or deposition as the tidal velocity approaches $0.0 \mathrm{~cm} \mathrm{~s}^{-1}$ at high tide.

A statistical analysis was also used to estimate the net flux of each constituent through Stns 1 and 2 within the flume for the period from 19 Jun 1983 through 18 Jun 1984. During this time there were 707 tidal cycles. A common method for estimating an annual net flux has been to determine the net flux for a set number of cycles per year, take the average, and multiply by the annual number of cycles. In the presence of the flux/

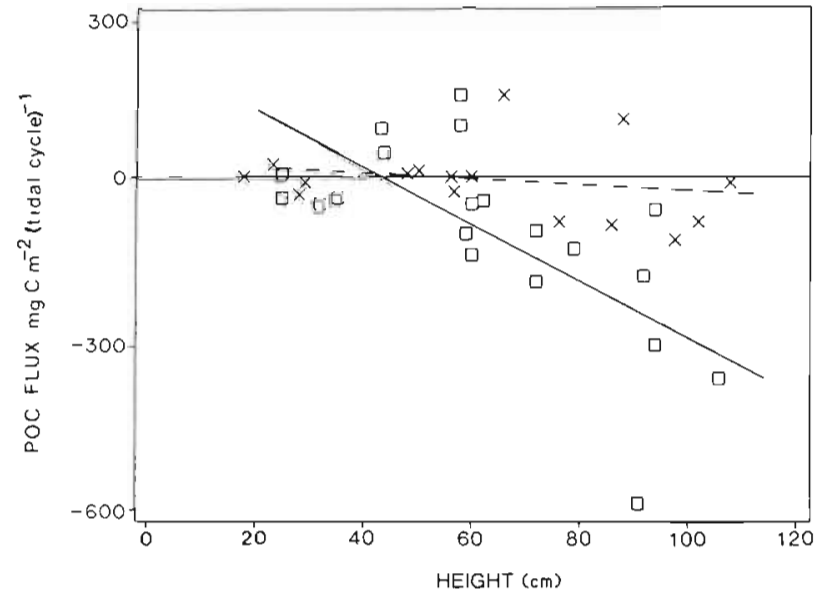

Fig. 6. Net POC flux (whole marsh) as a function of maximum tidal height. $(x)$ Winter; (c) summer

cycle variability that we anticipated, and eventually did see, this technique leads to estimates which are at least highly variable and can be biased. Based on these factors, it was decided to use a regression estimator (Cochran 1977, Chap. 7) to approximate the net flux of the carbon species on an annual basis. The primary purpose in building these regression models was to obtain the best possible estimate of annual transport rather than judge the effects of the predictor variables. There were several competing models that were almost as good as those selected and the fact that a predictor variable is or is not in the model cannot be taken to imply the presence or absence of an absolute causeeffect relationship on transport. The regression models used to calculate monthly and annual fluxes during tidal inundation are listed in Table 4 , while the actual fluxes and relative contribution of each marsh zone are listed in Tables $5 \& 6$. Since we did not have adequate information to estimate the annual export from the marsh via runoff and seepage in the same detailed manner, a mean export tide ${ }^{-1}$ was determined, and this

Table 3. Correlation analysis between net carbon flux per tidal cycle (Stns 1 and 2) and physical and chemical parameters. Chemical variables are flood tide means for the tidal cycles measured; physical variables are explained in Table 1

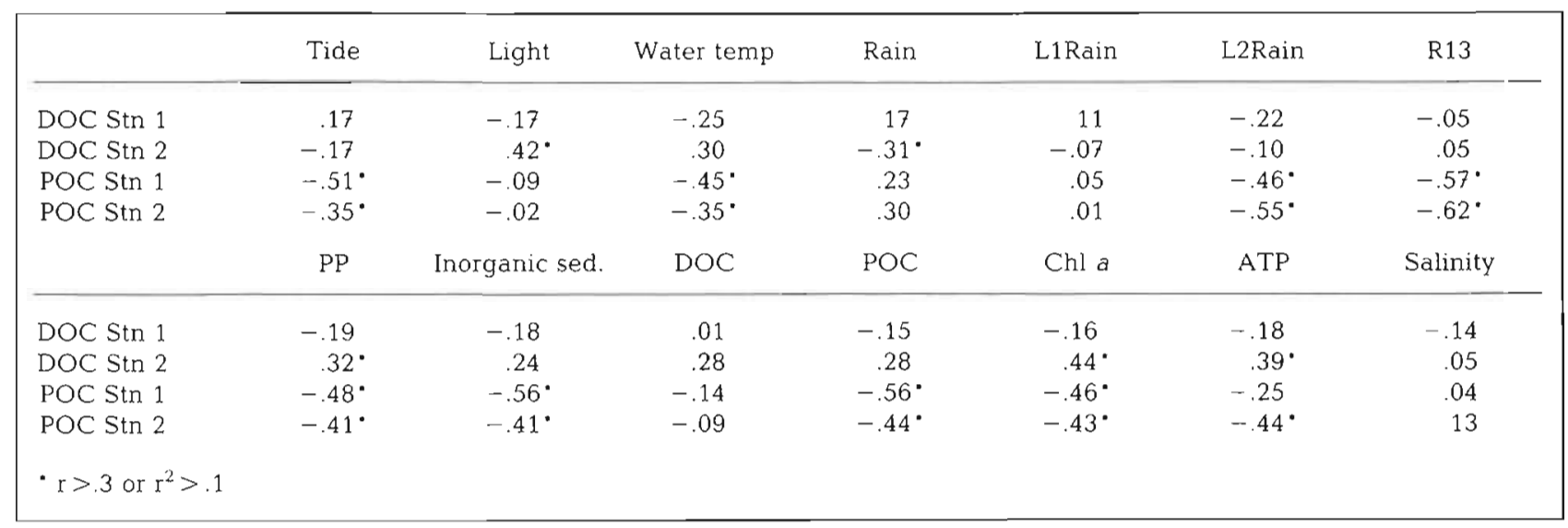


Table 4. Regression models used to calculate monthly and annual fluxes

\begin{tabular}{lccr|}
\hline & DOC & & \\
Variable & Parameter estimate & Variable & PoC \\
Stn 1 & & & 0.065130 \\
INTERCEPT & 0.002551 & INTERCEPT & -0.000325 \\
RAIN & -0.008274 & L2 TIDE & 0.011081 \\
L2 RAIN & -0.048569 & RAIN & -0.034226 \\
R13 & 0.003655 & L2 RAIN & -0.012000 \\
AWNDWT & -0.000231 & R13 & \\
Stn 2 & & & 0.020611 \\
INTERCEPT & -0.006320 & INTERCEPT & -0.000084 \\
RAIN & -0.015040 & L2 TIDE & 0.010820 \\
LIGHT2 & 0.023180 & RAIN & -0.058290 \\
& & L2 RAIN & -0.032632 \\
& & LIGHT & 0.028188 \\
\hline
\end{tabular}

Table 5. Monthly and annual net flux estimates [gC (time $)^{-1}$ ] through Stns 1 and $2 ;(-)$ import, (+) export

\begin{tabular}{|c|c|c|c|c|c|}
\hline \multirow[b]{2}{*}{ Date (1983-1984) } & \multirow[b]{2}{*}{ No. of tidal cycles } & \multicolumn{2}{|c|}{ Stn 1 (whole marsh) } & \multicolumn{2}{|c|}{ Stn 2 (high marsh) } \\
\hline & & DOC & $\mathrm{POC}$ & DOC & POC \\
\hline Jun 19-Jul 18 & 58 & -9 & - 608 & 181 & -425 \\
\hline Jul 19-Aug 18 & 60 & -42 & -862 & 136 & -515 \\
\hline Aug 19-Sep 18 & 60 & -91 & -1373 & -20 & -729 \\
\hline Sep $19-$ Oct 18 & 58 & 20 & -910 & 12 & -498 \\
\hline Oct $19-$ Nov 18 & 59 & 22 & -917 & -63 & -502 \\
\hline Nov $19-D e c 18$ & 58 & 16 & -461 & -100 & -378 \\
\hline Dec $19-\operatorname{Jan} 18$ & 60 & -149 & -520 & -64 & -435 \\
\hline Jan $19-$ Feb 18 & 60 & -173 & -517 & -67 & -431 \\
\hline Feb 19-Mar 18 & 56 & -33 & -803 & 24 & -524 \\
\hline Mar 19-Apr 18 & 60 & -39 & -1092 & 76 & -655 \\
\hline Apr 19-May 18 & 58 & -82 & -1113 & 197 & -630 \\
\hline May 19-Jun 18 & 60 & 208 & -653 & & -399 \\
\hline Annual summary & 707 & -351 & $-9830^{\circ}$ & $201^{\circ}$ & $6122^{\circ}$ \\
\hline SE for annual budget & & 1240 & 1315 & 101 & 1790 \\
\hline Model $r^{2}$ & & 0.55 & 0.76 & 0.37 & 0.39 \\
\hline
\end{tabular}

value was multiplied by 707 . In this calculation tides associated with rainstorms were evaluated separately for POC (Table 6). In order to accomplish this a regression was made of POC export via runoff and seepage versus magnitude of rainfall. This formula was used to evaluate the total export of this constituent from the marsh when rain occurred during tidal exposure over an annual cycle.

This study suggests that on an annual basis the vegetated marsh was a sink (statistically significant, $\alpha=0.05$ ) for POC and neutral with respect to the exchange of DOC during tidal inundation (Tables 5 and 6). These results compare favorably with a flume study conducted on Sapelo Island, Georgia (Chalmers et al. 1985). Both studies imply that if labile compounds were released directly into the inundating tidal water by Spartina leaves (Turner 1978, Pakulski 1986) or from the marsh surface via diffusion (Pomeroy et al. 1977), then they were removed from the tidal water before it left the marsh surface. This supports the earlier work by Gallagher et al. (1976) which suggested that DOC exudates from live Spartina leaves were quickly removed by epiphytic organisms. This study also suggests this marsh exports large amounts of POC and DOC via runoff and seepage due to the storage and consequent release of water from the high marsh during low tide exposure. However, the specific export of $\mathrm{POC}$ via runoff following rainstorms was less in our 
Table 6. Annual flux estimates for the marsh flume and weir study; $(-)$ import, $(+)$ export

\begin{tabular}{|lrc|}
\hline & $\begin{array}{c}\text { Carbon flux }\left(\mathrm{gC} \mathrm{m}^{-2} \mathrm{yr}^{-1}\right) \\
\text { POC }\end{array}$ \\
\hline Marsh flume & & \\
whole marsh (Stn 1) & -2.9 & -83.3 \\
high marsh (Stn 2) & 2.1 & -64.4 \\
low marsh & 24.0 & -161.2 \\
Weir (whole marsh) & 36.2 & 16.7 (non-storm) \\
& & 13.9 (storm) \\
Annual net flux & 33.3 & -52.7 \\
(whole marsh) & & \\
\hline
\end{tabular}

study than that found by Chalmers et al. (1985). This phenomenon may be due to lack of fine clay in our high marsh which is vegetated by medium and short Spartina. This characteristic is a byproduct of the immature or young status of the Bly Creek basin (Gardner \& Bohn 1980). In addition, regardless of season, there was a negligible amount of detrital organic material on the marsh surface. However, it must be stressed that in both studies the export of POC from the marsh via runoff and seepage (including rainstorms) was less than or equal to that imported via tidal inundation on an annual basis.

As stated in the introduction, the results from carbon transport studies in tidal creeks support the outwelling hypothesis. On the basis of this research, Nixon (1980) estimated that marsh-estuarine systems outwell between 100 and $300 \mathrm{~g} \mathrm{C} \mathrm{m}^{-2} \mathrm{yr}^{-1}$. The results from the present study coupled with the flume study conducted on Sapelo Island (Chalmers et al. 1985) suggest the vegetated marsh subsystem is a sink for POC. The present study also implies the vegetated marsh is neutral or exports small quantities of DOC. These results suggest the vegetated marsh cannot account for the observed export of POC in the carbon transport studies through tidal creeks, whereas some of the outwelled DOC may be attributed to runoff and seepage from the marsh surface during low tide exposure. However, if this marsh did not have the topographic low in the short Spartina zone, then (1) the runoff and seepage of water and material would have been an order of magnitude lower, and (2) the net DOC exchange between the marsh and the adjacent tidal creek would be negligible.

It is suggested that most of the outwelled DOC from wetlands through tidal creeks has its source in groundwater advection, water column processes, and/or freshwater inputs. The latter has been shown to be important in the North Inlet system (Wolaver et al. 1986). Because the vegetated marsh appears to be a sink for POC, the particulate carbon outwelled through tidal creeks may have its source in scoured feeder tidal creeks and creek banks via rainstorms, resuspension of creek bottom materials, and/or primary and secondary production in the tidal water However, there are several pathways by which POC can be exported from the marsh surface which have not been investigated. These include wrack (macrodetritus) movement during severe storms when the marsh is inundated, carbon export via motile organisms (fish), and/or dead Spartind stems falling into the tidal creek from the low marsh berm. The amount of wrack floating on the water surface which was exported through North Inlet was found to be less than $1 \%$ of above-ground Spartina productivity, suggesting this process may be insignificant in this marsh (Dame 1982). Chalmers et al. (1985) also concluded that wrack movement contributed little to the carbon balance in a Georgia salt marsh. However, wrack may also enter the water column, decompose on the creek bottom, and eventually exit the system. This study suggests we may have to reexamine our impression of how the vegetated marsh subsystem processes carbon. It was originally construed as being an open system which in essence exported large amounts of organic material. This study suggests the vegetated marsh may export a relatively small amount of POC and DOC via runoff and seepage during low tide exposure; the particulate exports may be associated with high POC loading in the adjacent tidal creek. However, on an annual basis the marsh imports POC due to the relatively large removal of this constituent from the tidal water as it resides on the marsh surface. This study also suggests that total organic exchange (DOC + POC) between the vegetated marsh and the adjacent tidal creek is negligible.

\section{CONCLUSIONS}

Flume and weir studies were used to evaluate carbon exchange (DOC and POC) between a euhaline vegetated marsh and the adjacent tidal creek. The flume study estimated the net carbon exchange with the marsh during tidal inundation while the weir study measured the export from the marsh via runoff and seepage during low tide exposure (including rain events). Mean flood water DOC concentrations varied seasonally between 3.1 and $18.6 \mathrm{ppm}$ with higher concentrations observed during late spring. This trend is negatively associated with freshwater discharge, suggesting the ultimate source of the DOC resides in the adjacent forested uplands. DOC flux data show there was a statistically insignificant $(\alpha=0.05)$ import to the marsh of $2.9 \mathrm{~g} \mathrm{C} \mathrm{m}^{-2} \mathrm{yr}^{-1}$.

Mean POC flood water concentrations varied season- 
ally between 0.7 and $4.6 \mathrm{ppm}$ with higher values observed during summer. The POC flux data show there was a statistically significant $(\alpha=0.05)$ import to the marsh of $83.3 \mathrm{~g} \mathrm{C} \mathrm{m}^{-2} \mathrm{yr}^{-1}$, with the largest removal rate observed as the tidal water resided on the low marsh (tall Spartina). A correlation analysis suggests the transport of this constituent is controlled by POC load, water temperature, tidal height (duration of tidal inundation) and storms. DOC and POC exports from the marsh during low tide exposure via runoff and seepage were 36.2 and $30.6 \mathrm{~g} \mathrm{C} \mathrm{m}^{-2} \mathrm{yr}^{-1}$, respectively. Total exchange of carbon (flume + weir studies) between the vegetated marsh and the adjacent tidal creek suggests this system is a sink for POC and a source of DOC, with the total organic carbon exchange being negligible. This study implies the vegetated marsh may not be the source of carbon which was found to outwell from this and other marsh-estuarine systems.

Acknowledgements. These data were collected with the help of an interdisciplinary research group supported by NSF grant DEB 8119752. Special thanks to Mac Mitchell, Steve Hutchinson, Bob McLaughlin, Helen Tarbox, Virginia Smith and Anne Miller for their technical assistance.

\section{LITERATURE CITED}

Chalmers, A. G., Wiegert, R. G., Wolf, P. L. (1985). Carbon balance in a salt marsh: interactions of diffusive export tidal deposition and rain fall caused erosion. Estuar. coast. Shelf Sci. 21: 757-771

Chrzanowski, T. H., Stevenson, L. H., Spurrier, J. D. (1982). Transport of particulate organic carbon through the North Inlet ecosystem. Mar Ecol. Prog. Ser. 7: 231-245

Chrzanowski, T H., Stevenson, L. H., Spurrier, J. D. (1983) Transport of dissolved organic carbon through a major creek of the North Inlet ecosystem. Mar. Ecol. Prog. Ser 13: $167-174$

Cochrans, W. G. (1977). Sampling techniques, 3rd edn. Wiley, New York

Dame, R. F. (1982). The flux of floating macrodetritus in the North Inlet estuary. Estuar. coast. Shelf Sci. 15: 337-344

Gallagher, J. L., Pfeiffer, W. J., Pomeroy, L. R. (1976). Leaching and microbial utilization of dissolved organic carbon from leaves of Spartina alterniflora. Estuar. coast. mar. Sci. 4: $467-471$

Gardner, L. R. (1975). Runoff from an intertidal marsh during tidal exposure-recession curves and chemical characteristics. Limnol. Oceanogr 20: 81-89
Gardner, L. R., Bohn, M. (1980). Geomorphic and hydraulic evolution of tidal creeks on a subsiding beach ridge plain, North Inlet, S. Carolina. Mar. Geol. 34: M91-M97

Happ, G., Gosselink, J. G., Day, J. R. (1977). The seasonal distribution of organic carbon in a Louisiana estuary. Estuar. coast. mar. Sci. 5: 695-705

Heinle, D. R., Flemer, D. A. (1976). Flows of materials between poorly flooded tidal marshes and an estuary. Mar. Biol. 35: 359-373

Mallows, C. L. (1973). Some comments on Cp. Technometrics 15: $661-675$

Moore, K. A. (1974). Carbon transport in two York River Virginia marshes. M.S. thesis, Univ. of Virginia, Charlottesville

Nixon, S. W. (1980). Between coastal marshes and coastal waters - a review of twenty years of speculation and research in the role of salt marshes in estuarine productivity and water chemistry. In: Hamilton, R., MacDonald, K. B. (eds.) Estuarine and wetland processes. Plenum Press, New York, p. 437-525

Odum, E. P., de la Cruz, A. A. (1967). Particulate organic detritus in a Georgia salt marsh - estuarine ecosystem. In: Lauff, G. H. (ed.) Estuaries. American Association for the Advancement of Science, Washington, D. C. Publication No. 83, p. $383-388$

Pakulski, J. D. (1986). The release of reducing sugars and dissolved organic carbon from Spartina alterniflora in a Georgia salt marsh. Estuar. coast. Shelf Sci. 22: 385-394

Pomeroy, L. R., Bancroft, K., Breed, J., Christian, R. R., Frankenberg, D., Hall, J. R., Maurer, L. G., Wiebe, W. J., Wiegert, R. G., Wetzel, R. L. (1977). Flux of organic matter through a salt marsh. In: Wiley, M. (ed.) Estuarine processes, Vol. 2. Academic Press, New York, p. 270-279

Turner, R. E. (1978). Community plankton respiration in a salt marsh estuary and the importance of macrophyte leacheates. Limnol. Oceanogr. 23: 442-451

Valiela, I., Teal, J. M., Volkman, S., Shafer, D., Carpender, E. J. (1978). Nutrient and particulate fluxes in a salt marsh ecosystem: tidal exchanges and inputs by precipitation and groundwater Limnol. Oceanogr. 23 (4): 798-812

Wolaver, T G., Hutchinson, S., Marozas, M. (1986). Dissolved and particulate organic carbon in the North Inlet Estuary, South Carolina - what controls their concentrations? Estuaries 9 (1): 31-38

Wolaver, T G., Whiting, G., Kjerfve, B., McKellar, H., Zingmark, R., Dame, R., Chrzanowski, T C., Spurrier, J., Williams, T (1985). The flume design - a methodology for evaluating material fluxes between a vegetated salt marsh and the adjacent tidal creek. J. exp. mar Biol. Ecol. 91 281-291

Woodwell, G. M., Whitney, D. E, Hall, C. A. S, Houghton, R. A. (1977). The Flax Pond ecosystem study - exchanges of carbon in water between a salt marsh and Long Island Sound. Limnol. Oceanogr 22 (5): 833-838 